\title{
Dietary intakes and health-related behaviours of Korean American women born in the USA and Korea: The Multiethnic Cohort Study
}

\author{
Song-Yi Park*, Suzanne P Murphy, Sangita Sharma and Laurence N Kolonel \\ Cancer Etiology Program, Cancer Research Center of Hawaii, University of Hawaii, 1236 Lauhala Street, Suite 407, \\ Honolulu, HI 96813, USA
}

Submitted 19 November 2004: Accepted 24 March 2005

\begin{abstract}
Objective: This study assessed and compared heath-related behaviours and nutrient and food group intakes between US-born and Korea-born Korean American women. Design and subjects: Cross-sectional analyses were performed for ethnic Koreans who participated in the Multiethnic Cohort Study in Hawaii and Los Angeles in 19931996. The sample included 492 Korean American women aged $45-75$ years who were born in the USA $(n=274)$ or Korea $(n=218)$. Participants were recruited using driver's license files as a primary sampling source and completed a self-administered questionnaire, including a quantitative food frequency section.

Results: The proportion overweight or obese was 31.4\% in US-born and $9.4 \%$ in Korea-born women. US-born women had higher intakes of total fat and fat as a percentage of energy, and lower intakes of sodium, vitamin $\mathrm{C}, \boldsymbol{\beta}$-carotene and carbohydrate as a percentage of energy, than Korea-born women. Comparing intakes of food group servings from the Food Guide Pyramid, US-born women reported more whole grains, red meat and nuts, and less soy products, than did Korea-born women. US-born women also consumed fewer vegetables and fruit than those born in Korea. Few women in either group reported intakes that met the recommendations for dairy foods. Intake of discretionary fat from the Pyramid tip was higher in US-born than in Korea-born women.

Conclusions: These findings indicate that the acculturation of Korean immigrants affects dietary intakes in ways that may alter risks of several chronic diseases. Further studies will be necessary to examine the effects of dietary acculturation on disease patterns.
\end{abstract}

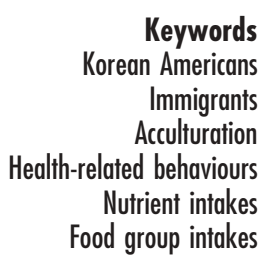

Diet is one of the numerous changes occurring as a result of immigration, and has become an important issue in public health nutrition. A substantial shift to a Western lifestyle appears to result in modified morbidity and mortality from many chronic diseases ${ }^{1}$. Dietary changes observed in Asian Americans, including increased intakes of total energy and fat, have been hypothesised to be risk factors for various chronic diseases ${ }^{2-4}$. Therefore, the study of dietary changes after immigration may provide information on how to intervene on the negative and adopt the positive aspects of diets in Western counties ${ }^{1}$.

Korean Americans are a rapidly growing Asian group in the USA and now number over one million ${ }^{5}$. Although there are still relatively few studies compared with those for Japanese and Chinese, several researchers have been focusing on diverse aspects of Korean Americans' diets. Dietary quality and nutritional status have been studied for more than 20 years $^{6-10}$. One study developed and validated a food-frequency questionnaire for Korean Americans ${ }^{11}$.
Recently, several studies were performed to compare diets by acculturation status, which was measured by a variety of methods ${ }^{12-15}$. The subjects of these studies were mostly immigrants who were born in Korea or their children, because the immigration history of Koreans to the USA is relatively short. The first wave of immigration was in 1903 when Korean workers arrived in Hawaii ${ }^{16}$. However, the main wave of migration did not begin until the US Immigration Act of $1965^{17}$. Although a substantial number of ethnic Koreans have not lived in the USA long enough to have several generations for observation, dietary studies have shown significant differences in diet by acculturation status, including a higher intake of fat as a percentage of energy or lower intake of vegetables in more acculturated groups, no matter how diet was assessed or acculturation status was measured ${ }^{12-15}$. Studies of diet in Korean immigrants may help explain the higher rate of overweight in Korean Americans compared with Koreans living in Korea $^{18}$. In particular, studies including subsequent 
generations as well as first immigrants can show more obvious dietary differences due to place of birth or time of stay in the USA.

The Multiethnic Cohort Study in Hawaii and Los Angeles targeted five ethnic groups: African Americans, Latinos, Japanese Americans, Native Hawaiians and Whites. Since sampling of subjects for the study was based on ethnicspecific surname or first name, a small proportion of Korean participants were selected unintentionally ${ }^{19}$. The sample was a mixed group of Korean American adults that ranged from recent immigrants to descendents of early immigrants. The aim of the present study was to assess and compare nutrient and food group intakes between USborn and Korea-born Korean American women.

\section{Subjects and methods}

\section{Multietbnic cobort}

The Multiethnic Cohort included more than 215000 individuals living in Hawaii and Los Angeles. This large prospective cohort was designed to examine the relationship of diet and other risk factors to cancer among representative population groups. To establish a cohort based on a representative sample of the population, several sampling sources were used: driver's license files which included the names of most resident adults as a primary source, the voter's registration file in Hawaii, and the Health Care Financing Administration files in California. In order to minimise the inclusion of subjects other than the targeted ethnic groups, ethnic-specific surname and first-name lists were compiled. However, since these were not totally specific, a number of persons of ethnicities other than the five that were targeted responded at baseline ${ }^{19}$. More than 500 Koreans were selected because they had a surname used in common with one or more of the targeted ethnic groups or had changed their name after marriage to a man of a different ethnicity. For that reason, Koreans in the Multiethnic Cohort were mostly women. Because ethnic Koreans in the cohort were not followed prospectively, only cross-sectional analyses could be performed for this study.

\section{Baseline questionnaire}

Baseline information was collected during 1993-1996 for adults aged 45-75 years. Each participant completed a mailed self-administered questionnaire. The questionnaire included a quantitative food-frequency questionnaire (QFFQ) designed from 3-day measured food records. Foods that contributed at least $85 \%$ of the intake of fat, dietary fibre, vitamin A, carotenoids and vitamin $\mathrm{C}$ were selected. A calibration sub-study was conducted and showed satisfactory correlations (0.55-0.74) between energy-adjusted daily nutrient estimates from the QFFQ and three 24-hour recalls ${ }^{20}$. The QFFQ had eight frequency categories for foods (ranging from never or hardly ever to two or more times a day) and nine for beverages (from never or hardly ever to four or more times a day), with three choices of portion size. Photographs showing selected foods in representative portion sizes were provided at the top of several pages of the questionnaire as an aid to quantification. Energy and nutrient intakes were calculated from the QFFQ using the food composition table that has been developed and maintained at the Cancer Research Center of Hawaii $(\mathrm{CRCH})$ for use in the Multiethnic Cohort Study ${ }^{19}$.

In addition to the QFFQ, the questionnaire included information on demographic, lifestyle and medical history items. For example, participants were asked to respond to whether they used eight types of supplements during the past year and select the frequency category (ranging from one to three per week to three or more a day). For physical activity, they were asked how many hours a week they spent in strenuous sport, vigorous work and moderate activity, with examples for each activity. Self-reported height and weight information was used to calculate body mass index (BMI, weight in kilograms divided by the square of height in metres). Those with a BMI of $25 \mathrm{~kg} \mathrm{~m}^{-2}$ or more were classified as overweight or obese. Descriptive data for the sample have been published ${ }^{19}$.

\section{Sample size}

Among approximately 215000 respondents at baseline, Koreans were selected based on self-reported information on ethnic or racial background. Respondents were allowed to record multiple races for parents as well as themselves. Five hundred and seventy persons answered the self-identified ethnicity question as 'Korean' without indicating any other ethnicity and were classified as Korean subjects for this study. The majority of Korean respondents (91.4\%) were women; because of the small sample of men, only women were included in the analyses. To achieve a homogeneous sample, 29 women who identified themselves as Korean but were born in countries other than Korea and the USA were excluded. Thus, 492 women were included in the analyses.

\section{Pyramid servings}

The US Department of Agriculture's Pyramid Servings Database identifies the number of servings of 30 Food Guide Pyramid food groups that are provided by $100 \mathrm{~g}$ of a wide variety of foods reported during the 1994-1996 Continuing Survey of Food Intake by Individuals $(\mathrm{CSFII})^{21,22}$. Foods that were mixtures were first disaggregated into their components and each ingredient was assigned to the appropriate Pyramid food group. The $\mathrm{CRCH}$ food composition table was linked to this database so Pyramid servings could be calculated for foods that are eaten in Hawaii, but are not included in the CSFII national survey $^{23}$. Food Guide Pyramid servings of many traditional mixtures consumed in Hawaii were determined using local recipes. The daily number of Food Guide Pyramid servings was computed for each individual by summing the servings across the reported food items, as previously described ${ }^{24,25}$. 


\section{Statistical analyses}

Descriptive statistics were performed with SAS software, version $8.02^{26}$. Subjects were divided into two groups, USborn and Korea-born, based on the response to the question on place of birth. Because of an unequal age distribution between the two groups, comparative analyses were conducted using the SAS general linear model procedure with least square means to control for age. Age-adjusted means for proportions were computed using a binary dependent variable. Health-related characteristics were adjusted for both age and education level. Intakes of nutrients and foods were adjusted for BMI, smoking status and physical activity, in addition to age and education level. Significant differences in adjusted means between two groups were determined using $t$-tests.

\section{Results}

\section{General characteristics of subjects}

Table 1 shows the general characteristics of Korean American women in this sample. US-born women were older than Korea-born women by an average of 9 years.

Table 1 Characteristics of Korean American women in the Multiethnic Cohort in Hawaii and Los Angeles, 1993-1996

\begin{tabular}{|c|c|c|}
\hline & $\begin{array}{l}\text { US-born } \\
(n=274)\end{array}$ & $\begin{array}{c}\text { Korea-born } \\
(n=218)\end{array}$ \\
\hline Age (years), mean \pm SD $\dagger$ & $62.5 \pm 8.4$ & $53.5 \pm 6.6$ \\
\hline \multicolumn{2}{|l|}{ Years of stay in the USA (\%)‡ } & 15.1 \\
\hline $16-25$ & & 46.8 \\
\hline$\geq 26$ & & 38.1 \\
\hline \multicolumn{3}{|l|}{ Area of residence (\%) } \\
\hline Hawaii & 93.4 & 91.3 \\
\hline Los Angeles & 6.6 & 8.7 \\
\hline \multicolumn{3}{|l|}{ Birthplace of mother (\%) } \\
\hline USA & 34.7 & 0.5 \\
\hline Korea & 64.6 & 99.5 \\
\hline Other & 0.7 & 0.0 \\
\hline \multicolumn{3}{|l|}{ Birthplace of father (\%) } \\
\hline USA & 26.7 & 0.5 \\
\hline Korea & 71.8 & 99.0 \\
\hline Other & 1.5 & 0.5 \\
\hline \multicolumn{3}{|l|}{ Marital status (\%) } \\
\hline Married & 65.2 & 76.6 \\
\hline Separated or divorced & 18.7 & 11.5 \\
\hline Widowed & 15.8 & 11.9 \\
\hline Never married & 0.4 & 0.0 \\
\hline \multicolumn{3}{|l|}{ Education $(\%)$} \\
\hline$\leq 8$ th grade & 1.8 & 21.2 \\
\hline $9-10$ th grade & 5.1 & 12.0 \\
\hline $11-12$ th grade & 39.6 & 29.0 \\
\hline Vocational/some college & 24.2 & 19.8 \\
\hline$\geq$ College graduate & 29.3 & 18.0 \\
\hline \multicolumn{3}{|l|}{ Number of children (\%) } \\
\hline None & 7.3 & 19.9 \\
\hline $1-2$ & 38.8 & 56.5 \\
\hline $3-4$ & 38.8 & 19.4 \\
\hline$\geq 5$ & 15.0 & 4.2 \\
\hline Ever employed (\%) & 89.1 & 77.5 \\
\hline
\end{tabular}

SD - standard deviation.

$\dagger$ Age at baseline (completion of the quantitative food-frequency questionnaire).

$\ddagger$ Korea-born only.
The majority of the Korea-born women (62\%) had lived in the USA for less than 25 years. Most subjects were residents of Hawaii because recruitment for the cohort in Hawaii targeted individuals with Asian surnames. Among US-born women, $35.4 \%$ had at least one parent born in the USA. The proportion of subjects who were separated or divorced was higher in US-born than in Korea-born women. US-born women had a higher educational level and had more children than did Korea-born women. More US-born women reported they had been employed at some time in their lives.

\section{Health-related characteristics}

The average BMI was significantly higher in US-born subjects $\left(23.6 \mathrm{~kg} \mathrm{~m}^{-2}\right)$ than in those born in Korea $\left(22.1 \mathrm{~kg} \mathrm{~m}^{-2}\right.$ ) after age and education adjustment (Table 2 , $P<0.001$ ). The proportion overweight or obese was $31.4 \%$ in US-born women and $9.4 \%$ in Korea-born women. More US-born women were former smokers while the proportion of current smokers was similar between the two groups. There were no significant differences in drinking, physical activity and supplement use between the two groups. Similar numbers of women in both groups reported they had used a vitamin and/or mineral supplement at least once a week during the past year. More US-born women who were postmenopausal reported that they used oestrogen drugs than did Korea-born women. Also, more US-born women reported that they had ever had a mammogram or Pap smear than did Korean-born women. More US-born women (41.7\%) answered that they had family member who had been diagnosed with cancer than Korea-born women (22.1\%), but there was no difference in personal history of cancer between the two groups.

\section{Intakes of nutrients and Pyramid food group servings}

Daily energy and nutrient intakes for US-born and Koreaborn women are compared in Table 3. The table also presents the Recommended Dietary Allowance (RDA)/ Adequate Intake (AI) for women of the subjects' ages ${ }^{27-31}$. US-born women had a higher intake of total fat (57.8 vs. $44.9 \mathrm{~g})$ and fat as a percentage of energy (28.8 vs. $22.6 \%$ ), and a lower intake of sodium (2808 vs. $3378 \mathrm{mg}$ ), vitamin C (152 vs. $194 \mathrm{mg}$ ), $\beta$-carotene (4537 vs. $5487 \mu \mathrm{g}$ ) and carbohydrate as a percentage of energy ( 55.7 vs. 61.9\%), than Korea-born women. Energy intakes were almost identical for the two groups (1746 vs. $1734 \mathrm{kcal}$ ), so similar differences were seen for nutrient intakes expressed as nutrient densities (intake per $1000 \mathrm{kcal}$, data not shown). However, the lower intakes of some nutrients for US-born women compared with Korea-born women became significant when they were expressed as a density: carbohydrate (142 vs. $157 \mathrm{~g} / 1000 \mathrm{kcal}, P<0.05)$, vitamin A (720 vs. $826 \mu \mathrm{g}$ retinol equivalents $/ 1000 \mathrm{kcal}, P<0.05)$, folate $(159$ vs. $183 \mu \mathrm{g} / 1000 \mathrm{kcal}, P<0.01)$ and dietary fibre (10.8 vs. $12.3 \mathrm{~g} / 1000 \mathrm{kcal}, P<0.01)$. 
Table 2 Distribution of health-related characteristics of Korean American women†

\begin{tabular}{|c|c|c|c|}
\hline & $\begin{array}{l}\text { US-born } \\
(n=274)\end{array}$ & $\begin{array}{l}\text { Korea-born } \\
(n=218)\end{array}$ & $\begin{array}{l}\text { Significance of } \\
\text { differences between } \\
\text { the two groups }\end{array}$ \\
\hline $\mathrm{BMI}\left(\mathrm{kg} \mathrm{m}^{-2}\right)$, mean $\pm \mathrm{SD}$ & $23.6 \pm 4.1$ & $22.1 \pm 4.2$ & *** \\
\hline Overweight or obese (BMI $\geq 25 \mathrm{~kg} \mathrm{~m}^{-2}$ ) (\%) & 31.4 & 9.4 & *** \\
\hline \multicolumn{4}{|l|}{ Smoking status (\%) } \\
\hline Never & 42.1 & 59.8 & ** \\
\hline Former & 35.3 & 20.7 & ** \\
\hline Current & 22.6 & 19.4 & NS \\
\hline Current drinking ( $\geq 1$ drink week $^{-1}$ ) (\%) & 15.0 & 14.3 & NS \\
\hline \multicolumn{4}{|l|}{ Physical activity $\left(\right.$ h day $\left.^{-1}\right)$, mean \pm SD } \\
\hline Strenuous sports & $0.11 \pm 0.44$ & $0.19 \pm 0.46$ & NS \\
\hline Vigorous work & $0.08 \pm 0.49$ & $0.13 \pm 0.50$ & NS \\
\hline Moderate activity & $0.88 \pm 1.12$ & $0.82 \pm 1.14$ & NS \\
\hline Dietary supplement use (\%)‡ & 71.7 & 73.4 & NS \\
\hline Oestrogen use $(\%) \S$ & 73.6 & 48.1 & $* \star *$ \\
\hline Mammogram (\%) & 92.5 & 85.2 & * \\
\hline Pap smear (\%) & 99.8 & 87.0 & *** \\
\hline Personal history of cancer (\%) & 7.9 & 7.1 & NS \\
\hline Family history of cancer (\%) & 41.7 & 22.1 & *** \\
\hline
\end{tabular}

BMI - body mass index; SD - standard deviation.

$\dagger$ Adjusted for age and education.

$\ddagger$ Used one or more of the following supplements at least once a week during the past year: multivitamin or multivitamins with minerals, vitamin $\mathrm{A}$, vitamin $\mathrm{C}$, vitamin $\mathrm{E}, \beta$-carotene, calcium, selenium or iron.

$\S$ Postmenopausal only.

${ }^{\star}, P<0.05 ;{ }^{\star \star}, P<0.01 ;{ }^{\star \star \star}, P<0.001 ;$ NS - not significant.

The total consumption of grain, dairy and meat group servings was not significantly different between the two groups (Table 4). However, within the meat group, US-born women reported significantly more red meat (1.4 vs. $1.1 \mathrm{oz})$, nuts $(0.17 \mathrm{vs} .0 .06 \mathrm{oz})$ and less soy products (0.11 vs. $0.26 \mathrm{oz}$ ) than did Korea-born women. US-born women also consumed more cheese and fewer vegetable and fruit servings. Intake of discretionary fat from the
Pyramid tip was higher in US-born ( $46.3 \mathrm{~g}$ ) than in Koreaborn women $(35.0 \mathrm{~g})$.

\section{Proportions not consuming recommended servings}

Figure 1 shows the proportion of individuals who did not meet the recommended number of Food Guide Pyramid servings for their reported energy intake category. Energy intake categories were $\leq 1600,1601-2200,2201-2800$

Table 3 Daily energy and nutrient intakes (mean \pm SD) of Korean American women†

\begin{tabular}{|c|c|c|c|c|}
\hline & $\begin{array}{l}\text { US-born } \\
(n=274)\end{array}$ & $\begin{array}{l}\text { Korea-born } \\
\quad(n=218)\end{array}$ & $\begin{array}{l}\text { Significance of } \\
\text { differences between } \\
\text { the two groups }\end{array}$ & $\begin{array}{l}\text { RDA/Al for } \\
\text { women }\end{array}$ \\
\hline Energy (kcal) & $1746 \pm 904$ & $1734 \pm 913$ & NS & \\
\hline Protein (g) & $63.6 \pm 38.3$ & $64.6 \pm 38.7$ & NS & 46 \\
\hline Total fat (g) & $57.8 \pm 34.8$ & $44.9 \pm 35.1$ & $\star * *$ & \\
\hline $\mathrm{P} / \mathrm{S}$ ratio & $0.96 \pm 0.30$ & $0.93 \pm 0.30$ & NS & \\
\hline Cholesterol (mg) & $169 \pm 135$ & $163 \pm 136$ & NS & \\
\hline Carbohydrate (g) & $245 \pm 135$ & $271 \pm 136$ & NS & 130 \\
\hline Calcium (mg) & $577 \pm 359$ & $580 \pm 363$ & NS & 1000/1200‡,§ \\
\hline Iron (mg) & $12.9 \pm 8.9$ & $13.4 \pm 9.0$ & NS & $18 / 8 \S$ \\
\hline Sodium (mg) & $2808 \pm 2066$ & $3378 \pm 2087$ & * & \\
\hline Vitamin A ( $\mu \mathrm{g} R E)$ & $1263 \pm 999$ & $1395 \pm 1009$ & NS & $700 \mu \mathrm{g}$ RAE \\
\hline Vitamin C (mg) & $152 \pm 138$ & $194 \pm 140$ & ** & 75 \\
\hline$\beta$-Carotene $(\mu \mathrm{g})$ & $4537 \pm 4172$ & $5487 \pm 4215$ & * & \\
\hline Vitamin $\mathrm{E}(\mathrm{mg} \alpha$-TE $)$ & $9.4 \pm 7.2$ & $9.4 \pm 7.3$ & NS & $15 \mathrm{mg} \alpha$-tocopherol \\
\hline Folate $(\mu \mathrm{g})$ & $280 \pm 225$ & $321 \pm 227$ & NS & $400 \mu \mathrm{g}$ DFE \\
\hline Dietary fibre (g) & $19.0 \pm 14.2$ & $21.5 \pm 14.4$ & NS & $25 / 21 \neq, \S$ \\
\hline$\%$ Energy from fat & $28.8 \pm 8.0$ & $22.6 \pm 8.1$ & $\star \star \star *$ & $20-359$ \\
\hline$\%$ Energy from protein & $14.2 \pm 3.2$ & $14.7 \pm 3.3$ & NS & $10-35$ \\
\hline$\%$ Energy from carbohydrate & $55.7 \pm 10.0$ & $61.9 \pm 10.1$ & $* * *$ & $45-65$ \\
\hline
\end{tabular}

SD - standard deviation; P/S - polyunsaturated fat (g)/saturated fat $(\mathrm{g})$; RE - retinol equivalents; $\alpha$-TE - $\alpha$-tocopherol equivalents; RDA Recommended Dietary Allowance; Al - Adequate Intake; RAE - retinol activity equivalents; DFE - dietary folate equivalents.

$\dagger$ Adjusted for age, education, body mass index, smoking status and physical activity. Intakes were from foods only, not from dietary supplements. $\ddagger$ Al.

$\S 31-50 />51$ years of age.

I Acceptable Macronutrient Distribution Range.

${ }^{\star}, P<0.05 ;{ }^{* *}, P<0.01 ;{ }^{* * *}, P<0.001 ; \mathrm{NS}-$ not significant. 
Table 4 Food Guide Pyramid servings intake per day (mean \pm SD) of Korean American women $\dagger$

\begin{tabular}{|c|c|c|c|}
\hline & $\begin{array}{l}\text { US-born } \\
(n=274)\end{array}$ & $\begin{array}{l}\text { Korea-born } \\
(n=218)\end{array}$ & $\begin{array}{l}\text { Significance of } \\
\text { differences between } \\
\text { the two groups }\end{array}$ \\
\hline Grain & $7.4 \pm 4.4$ & $7.8 \pm 4.4$ & NS \\
\hline Whole grains & $1.6 \pm 1.6$ & $1.2 \pm 1.7$ & ** \\
\hline Non-whole grains & $5.8 \pm 3.9$ & $6.6 \pm 3.9$ & * \\
\hline Vegetables & $4.2 \pm 3.5$ & $5.2 \pm 3.5$ & ** \\
\hline Dark green & $0.62 \pm 0.79$ & $0.69 \pm 0.80$ & NS \\
\hline Deep yellow & $0.45 \pm 0.62$ & $0.54 \pm 0.62$ & NS \\
\hline Potato & $0.29 \pm 0.27$ & $0.20 \pm 0.28$ & ** \\
\hline Starchy & $0.24 \pm 0.34$ & $0.19 \pm 0.34$ & NS \\
\hline Tomato & $0.47 \pm 0.50$ & $0.47 \pm 0.50$ & NS \\
\hline Other vegetables & $2.2 \pm 2.1$ & $3.1 \pm 2.1$ & $* * *$ \\
\hline Fruit & $2.7 \pm 3.4$ & $3.5 \pm 3.4$ & * \\
\hline Citrus, melons, and berries & $1.1 \pm 1.9$ & $1.7 \pm 1.9$ & ** \\
\hline Other fruit & $1.5 \pm 1.9$ & $1.8 \pm 1.9$ & NS \\
\hline Dairy & $0.80 \pm 0.72$ & $0.66 \pm 0.73$ & NS \\
\hline Milk & $0.51 \pm 0.61$ & $0.47 \pm 0.62$ & NS \\
\hline Yoghurt & $0.06 \pm 0.13$ & $0.04 \pm 0.14$ & NS \\
\hline Cheese & $0.23 \pm 0.29$ & $0.16 \pm 0.29$ & * \\
\hline Meat and meat alternatives (oz equivalents) & $4.2 \pm 3.5$ & $4.3 \pm 3.5$ & NS \\
\hline All meat, fish and poultry & $3.6 \pm 3.1$ & $3.6 \pm 3.1$ & NS \\
\hline Meat (beef, pork, veal, lamb, game) & $1.4 \pm 1.2$ & $1.1 \pm 1.2$ & * \\
\hline Organ meat & $0.01 \pm 0.06$ & $0.02 \pm 0.06$ & NS \\
\hline Frankfurter/sausage/lunch meats & $0.28 \pm 0.36$ & $0.22 \pm 0.37$ & NS \\
\hline Poultry & $1.2 \pm 1.6$ & $1.5 \pm 1.6$ & NS \\
\hline Fish & $0.66 \pm 0.90$ & $0.73 \pm 0.91$ & NS \\
\hline Egg & $0.23 \pm 0.30$ & $0.22 \pm 0.30$ & NS \\
\hline Soy & $0.11 \pm 0.28$ & $0.26 \pm 0.29$ & $* * *$ \\
\hline Nuts & $0.17 \pm 0.22$ & $0.06 \pm 0.23$ & *** \\
\hline Legumes & $0.14 \pm 0.54$ & $0.22 \pm 0.55$ & NS \\
\hline \multicolumn{4}{|l|}{ Pyramid Tip } \\
\hline Discretionary fat $(\mathrm{g})$ & $46.3 \pm 28.9$ & $35.0 \pm 29.2$ & *** \\
\hline Added sugars (tsp) & $8.9 \pm 8.4$ & $7.8 \pm 8.5$ & NS \\
\hline Alcohol (drinks) & $0.23 \pm 0.86$ & $0.15 \pm 0.87$ & NS \\
\hline
\end{tabular}

SD - standard deviation.

$\dagger$ Adjusted for age, education, body mass index, smoking status and physical activity.

${ }^{*}, P<0.05 ;{ }^{* \star}, P<0.01 ;{ }^{* \star}, P<0.001$; NS - not significant.

and $>2800 \mathrm{kcal}^{22}$. The proportions of subjects who fell into each range were 48\%, 31\%, 13\% and $8 \%$ for US-born, and 50\%, 27\%, 13\% and 10\% for Korea-born women, respectively, and were not significantly different between the two groups. More US-born women did not meet the recommended number of servings of vegetables and fruits (44.6 and 60.0\%, respectively) compared with Korea-born women (29.1 and 45.8\%, respectively). The percentage not consuming the recommended number of servings of dairy was very high in the both groups, 94.0\% in US-born and $95.1 \%$ in Korea-born women.

\section{Discussion}

In this study, dietary intakes and health-related behaviours of Korean American women who were born in Korea (first-generation immigrants) were compared with those who were born in the USA (second or subsequent generations). The subjects in this study are probably more acculturated than Korean Americans in other studies, because they were mostly living in Hawaii, and included many descendents of the earliest wave of immigrants. Some studies of Korean Americans have used the length of stay in the USA to measure the acculturation status of adults $^{32,33}$. Others considered several acculturation variables including English fluency and social participation at the same time $e^{10,12}$ or modified the scale which had been developed for Asian populations ${ }^{15}$. In this study, the generation of immigration was used to indicate acculturation status since more than half of the subjects were born in the USA, which meant they were at least the second generation to live in the USA. In these women, place of birth is also closely related to length of time in the USA, another measure of acculturation. The US-born women had lived in the USA much longer ( 62.5 years on average) than the Korea-born women, two-thirds of whom had lived in the USA less than 25 years. More acculturated immigrants tend to have high education level, high employment or high income ${ }^{12,14,15}$. A higher socio-economic status could result in a more Westernised lifestyle including diet.

A comparison by parents' place of birth within US-born subjects was also conducted: both parents born in Korea ( $n=175$ ) and one or both parents born in the USA $(n=97)$. However, there were no significant differences other than a small increase in intake of whole grains between these two groups. Health-related behaviours and intakes of nutrients and foods in Korean Americans were 


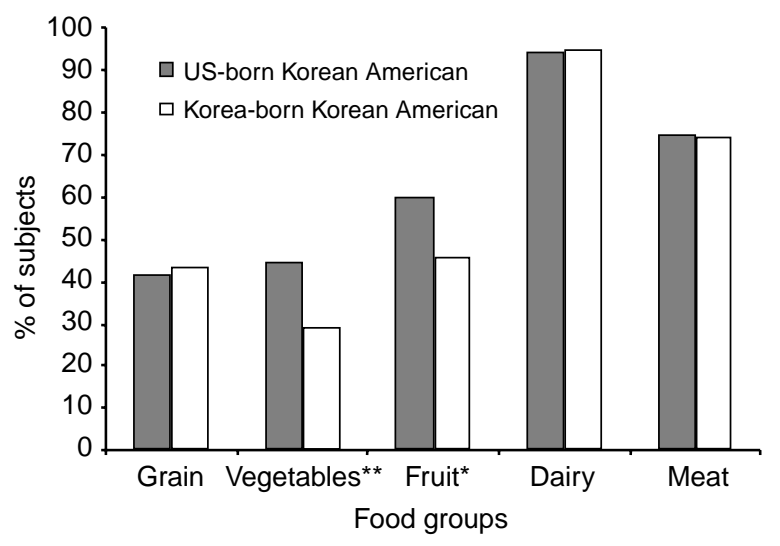

Fig. 1 The percentage (adjusted for age, education, body mass index, smoking status and physical activity) of subjects not consuming the recommended number of Food Guide Pyramid servings. The Food Guide Pyramid recommendations are based on daily energy intake: $0-1600 \mathrm{kcal}-6$ servings grain, 3 servings vegetables, 2 servings fruit, $2-3$ servings dairy, $5 \mathrm{oz}$ of meat or meat alternatives; $1601-2200 \mathrm{kcal}-6$ servings grain, 3 servings vegetables, 3 servings fruit, $2-3$ servings dairy, $5 \mathrm{oz}$ of meat or meat alternatives; $2201-2800 \mathrm{kcal}-9$ servings grain, 4 servings vegetables, 3 servings fruit, $2-3$ servings dairy, 6 oz of meat or meat alternatives; more than $2800 \mathrm{kcal}-11$ servings grain, 5 servings vegetables, 4 servings fruit, $2-3$ servings dairy, $7 \mathrm{oz}$ of meat or meat alternatives ${ }^{21}$. For dairy, the current recommendation for those older than 50 years is 3 servings, but 2 servings per day was used as the standard so we could compare with the previous study ${ }^{24,25}$. ${ }^{*}, P<0.05 ;{ }^{*}, P<0.01$ for differences between the two groups

affected by their place of birth, but not by their parents' place of birth.

The first wave of Korean immigration to the USA started in 1903 and ended in 1924. For the next 40 years, until the US Immigration Act of 1965, there were almost no immigrants from Korea ${ }^{16}$. Therefore, most Korean American women who were born in the USA were the children of the earliest immigrants. Korea-born women who immigrated after 1965 were relatively young, and therefore, at the time of the survey, they tended to be younger than the US-born women.

US-born Korean Americans in our study had a higher BMI $\left(23.6 \mathrm{~kg} \mathrm{~m}^{-2}\right.$ ) than those who were Korea-born $\left(22.1 \mathrm{~kg} \mathrm{~m}^{-2}\right)$ although both mean values were in the normal range ${ }^{34}$ of 18.5 to $24.9 \mathrm{~kg} \mathrm{~m}^{-2}$. Kim and Chan reported a mean BMI of $22.1 \mathrm{~kg} \mathrm{~m}^{-2}$ for Korean Americans, $86.4 \%$ of whom were Korea-born. However, they were much younger (36.9 years) than our subjects ${ }^{15}$. The proportion of women who were overweight or obese was three times as high in US-born women as in Koreaborn women in our study, even though both proportions were lower than in other ethnicities ${ }^{4}$. Although there was no statistically significant difference in physical activity, the mean hours of strenuous sports and vigorous work were lower in the US-born women, which could have an appreciable effect on weight gain over many years. This finding is consistent with other studies of Asian Americans, which have reported that the proportion of overweight or obese individuals increases for those who are US-born and have had a longer stay in the USA ${ }^{35}$. US-born women were more likely to use preventive medical services than were Korea-born women, as shown by the higher proportion using oestrogen and undergoing mammograms and Pap smears. Rates of Pap smear testing among Korean American women were higher in this study (99.8\% for US-born and $87.0 \%$ for Korea-born women) than in another study reporting only 63\% getting Pap tests ${ }^{36}$.

US-born Korean American women showed more Westernized dietary characteristics compared with those born in Korea. US-born women consumed more total fat and fat as a percentage of energy. The average energy from fat of US-born women was $28.8 \%$, which is below the upper limit of $35 \%$ recommended for adults by the Dietary Reference Intakes (DRIs) ${ }^{27}$. However, the higher proportion of those who are overweight or obese in USborn Korean American women may be explained in part by their higher consumption of fat than Korea-born women, although there was no statistically significant difference in energy intake. The average total cholesterol intake of both groups was still moderate compared with the upper limit of $300 \mathrm{mg} \mathrm{day}^{-1}$ recommended in the Dietary Guidelines for Americans ${ }^{37}$. Fat intakes of Korean American women in this study (28.8\% of energy for USborn and $22.6 \%$ for Korea-born women) were higher than in previous studies of Korean American adults. One study reported that the daily total fat intake of Korean American women (40-69 years) was only $16.0 \%$ of energy ${ }^{8}$. In another study, total fat intake of high and low acculturation groups (19-69 years) was 26.9\% and $24.3 \%$ of energy, respectively ${ }^{15}$. These results are consistent with other studies reporting that acculturation after immigration led to a higher fat intake in Asian immigrants ${ }^{38,39}$.

One characteristic of a traditional Korean diet is a high intake of sodium, which is derived mainly from kimchi, soup and dried or salted fish, all of which are very popular in the Korean diet. One study showed that $53 \%$ of Korean American adults had consumed more than $4800 \mathrm{mg}$ of sodium per day ${ }^{9}$. In the present study, US-born women consumed less sodium than did Korea-born women. However, the average intake was still higher than the upper limit of $2300 \mathrm{mg}$ recommended by the DRIs ${ }^{40}$. Furthermore, sodium intake in both groups is likely to be underestimated because it is difficult to capture salt added to foods at the table.

The calcium intake of Korean Americans is low, particularly for elderly Korean Americans, ${ }^{6,7}$. In the current study, Korean American women's mean calcium intake was less than $600 \mathrm{mgday}^{-1}$, which is very low compared with the $1200 \mathrm{mg}$ recommended as an AI in the DRIs ${ }^{28}$. The mean calcium intake was also lower than that of Japanese American and Pacific Islander women in the cohort $^{19}$. The main reason for low calcium intakes by Korean Americans is lower consumption of dairy products ${ }^{6,9}$, which is a typical 
problem in the traditional Korean diet. US-born women consumed more cheese than did Korea-born women, even though there was no significant difference in dairy product intake. However, consumption was still less than one serving per day in both groups. Most Korean American women (95\%) did not meet the recommend number of dairy servings for adults under 50 years of age (two per day), and were well below the three servings per day recommended for adults over 50 years $^{22}$. As previously reported, most Japanese American women in the cohort (95\%) did not meet the dairy recommendation, although dairy intakes were higher in non-Asian ethnic groups ${ }^{24,25}$.

Intakes of vitamin $C$ and $\beta$-carotene were higher in Korea-born women than in US-born women. The mean vitamin $C$ intakes of both groups were well above the RDA as a reference intake for an individual, while the mean intakes of vitamin $\mathrm{E}$ and folate were much lower than the RDAs. However, we were not able to calculate the prevalence of inadequacy for those micronutrients (i.e. the proportion of subjects with intakes less than the Estimated Average Requirement (EAR)) because the units for the EAR did not match the intake units for three of the four vitamins. Some of these differences in vitamin intakes can be explained by the different intakes of vegetables and fruits by the two groups. USborn Korean American women were less likely to meet the recommendations for the vegetable and fruit groups than were the Korea-born women. Lee et al. reported that acculturated Korean Americans consumed fewer vegetables but more fruit than traditional Korean Americans ${ }^{12}$.

In this study, it was possible to examine differences in the diets of Korean Americans by place of birth. Although the analyses provide important dietary data for Korean Americans at two levels of acculturation, there are some limitations to this study. First, the sample is not representative of all Korean Americans because it is not a random sample. Subjects were selected mainly from Hawaii and only Koreans with overlapping names for other ethnicities were included. This may have been a source of selection bias, perhaps better reflecting the dietary transition in Hawaii rather than in the rest of the USA. Furthermore, Korean women married to non-Korean men may be more acculturated than those married to ethnic Korean men. However, our findings are generally consistent with those reported by others ${ }^{12,15}$. Second, the self-administered QFFQ in the Multiethnic Cohort Study was not developed for Koreans. Therefore, there is a possibility that nutrient and food group intakes were underestimated in this group. However, many ethnic foods including Korean foods are consumed in Hawaii regularly by all ethnic groups ${ }^{19}$ and the QFFQ had almost 200 food items including traditional Korean foods such as kimchi, white rice, jook and several kinds of Korean soups. Therefore, it is likely that the QFFQ covered a considerable number of food items usually consumed by Koreans. Furthermore, there was not a large difference in energy intake between Korean Americans and another Asian American group for whom the questionnaire was designed, namely Japanese Americans (1738 and $1807 \mathrm{kcal}$, respectively). The two Asian American groups would be expected to have similar dietary intakes. Finally, there were no longitudinal data on the development of chronic diseases among the subjects. Therefore, it was not possible to examine how the diets of immigrants might affect risk of later disease. However, the higher overweight rate and higher fat intake for the US-born women may increase the risk of hypertension, cardiovascular disease and certain types of cancers.

In the present study, US-born Korean American women were more likely to be overweight or obese, and had a higher intake of energy from fat and a lower intake of fruit and vegetables, compared with Koreaborn women. However, they still had some typical features of traditional Korean diets such as low calcium and high sodium intakes. These findings support the hypothesis that the acculturation of immigrants may affect their diets in ways that influence their health. Therefore, it is important to provide education about the desirable aspects of both traditional Korean and Western diets in maintaining a healthful lifestyle. Community nutrition educators' efforts might focus on ways to keep fruit and vegetable intakes high and to increase dairy product consumption. Further studies will be necessary to examine the direct effects of dietary acculturation on disease patterns and whether interventions to improve the diets of Korean Americans can effectively reduce disease risk.

\section{Acknowledgements}

The authors wish to thank Jennifer F Yamamoto at the Cancer Research Center of Hawaii for her help with statistical analyses. This research was supported in part by the US National Institutes of Health (grant number R37 CA 54281 ) and by the Post-doctoral Fellowship Program of the Korea Science \& Engineering Foundation (KOSEF).

\section{References}

1 Satia-Abouta J, Patterson RE, Neuhouser ML, Elder J. Dietary acculturation: applications to nutrition research and dietetics. Journal of the American Dietetic Association 2002; 102: 1105-18.

2 Kin K, Lee JH, Kushida K, Sartoris DJ, Ohmura A, Clopton PL, et al. Bone density and body composition on the Pacific rim: a comparison between Japan-born and US-born JapaneseAmerican women. Journal of Bone Mineral Research 1993; 8: $861-9$.

3 Huang B, Rodriguez BL, Burchfiel CM, Chyou PH, Curb JD, Yano K. Acculturation and prevalence of diabetes among 
Japanese-American men in Hawaii. American Journal of Epidemiology 1996; 144: 674-81.

4 Davis J, Busch J, Hammatt Z, Novotny R, Harrigan R, Grandinetti A, et al. The relationship between ethnicity and obesity in Asian and Pacific Islander populations: a literature review. Ethnicity \& Disease 2004; 14: 111-8.

5 US Census Bureau. The Asian population: 2000, Census 2000 brief [online]. Available at http://www.census.gov/ prod/2002pubs/c2kbr01-16.pdf. Accessed 10 March 2005.

6 Kim KK, Kohrs MB, Twork R, Grier MR. Dietary calcium intakes of elderly Korean Americans. Journal of the American Dietetic Association 1984; 84: 164-9.

7 Kim KK, Yu ES, Liu WT, Kim J, Kohrs MB. Nutritional status of Chinese-, Korean-, and Japanese-American elderly. Journal of the American Dietetic Association 1993; 93: 1416-22.

8 Kim KK, Yu ES, Chen EH, Cross N, Kim J, Brintnall RA. Nutritional status of Korean Americans: implications for cancer risk. Oncology Nursing Forum 2000; 27: 1573-83.

9 Cross NA, Kim KK, Yu ES, Chen EH, Kim J. Assessment of the diet quality of middle-aged and older adult Korean Americans living in Chicago. Journal of the American Dietetic Association 2002; 102: 552-4.

10 Park SY, Paik HY, Skinner JD, Spindler AA, Park HR. Nutrient intake of Korean-American, Korean, and American adolescents. Journal of the American Dietetic Association 2004; 104: $242-5$.

11 Kim J, Chan MM, Shore RE. Development and validation of a food frequency questionnaire for Korean Americans. International Journal of Food Sciences and Nutrition 2002; 53: $129-42$

12 Lee SK, Sobal J, Frongillo EA Jr. Acculturation and dietary practices among Korean Americans. Journal of the American Dietetic Association 1999; 99: 1084-9.

13 Lee SK, Sobal J, Frongillo EA Jr. Acculturation, food consumption, and diet-related factors among Korean Americans. Journal of Nutrition Education 1999; 31: 321-30.

14 Park SY, Paik HY, Skinner JD, Ok SW, Spinder AA. Mothers' acculturation and eating behaviors of Korean American families in California. Journal of Nutrition Education and Behavior 2003; 35: 142-7.

15 Kim J, Chan MM. Acculturation and dietary habits of Korean Americans. British Journal of Nutrition 2004; 91: 469-78.

16 Nordyke EC. The Peopling of Hawaii. Honolulu: University of Hawaii Press, 1989.

17 Park IH. Korean Immigrants and US Immigration Policy. Honolulu: East-West Center, 1990.

18 Song YJ, Hofstetter CR, Hovell MF, Paik HY, Park HR, Lee J, et al. Acculturation and health risk behaviors among Californians of Korean decent. Preventive Medicine 2004; 39: $147-56$.

19 Kolonel LN, Henderson BE, Hankin JH, Nomura AM, Wilkens LR, Pike MC, et al. A multiethnic cohort in Hawaii and Los Angeles: baseline characteristics. American Journal of Epidemiology 2000; 151: 346-57.

20 Stram DO, Hankin JH, Wilkens LR, Pike MC, Monroe KR, Park S, et al. Calibration of the dietary questionnaire for a multiethnic cohort in Hawaii and Los Angeles. American Journal of Epidemiology 2000; 151: 358-70.

21 United States Department of Agriculture (USDA). The Food Guide Pyramid. Home and Garden Bulletin No. 252. Washington, DC: USDA, 1992

22 United States Department of Agriculture (USDA). Documentation: Pyramid Servings Database for USDA Survey Food Codes [online]. USDA, Agricultural Research Service, 2000. Available at http://www.ba.ars.usda.gov/cnrg/services/toc. html. Accessed 10 March 2005.

23 Sharma S, Murphy SP, Wilkens LR, Au D, Shen L, Kolonel LN. Extending a multiethnic food composition table to include standardized food group servings. Journal of Food Composition and Analysis 2003; 16: 485-95.

24 Sharma S, Murphy SP, Wilkens LR, Shen L, Hankin JH, Henderson B, et al. Adherence to the Food Guide Pyramid recommendations among Japanese Americans, Native Hawaiians, and whites: results from the Multiethnic Cohort Study. Journal of the American Dietetic Association 2003; 103: $1195-8$.

25 Sharma S, Murphy SP, Wilkens LR, Shen L, Hankin JH, Monroe KR, et al. Adherence to the Food Guide Pyramid Recommendations among African Americans and Latinos: results from the Multiethnic Cohort Study. Journal of the American Dietetic Association 2004; 104: 1873-7.

26 SAS Institute Inc. SAS Statistical Software System, Version 8.02. Cary, NC: SAS Institute Inc., 2001.

27 Institute of Medicine. Dietary Reference Intakes for Energy, Carbohydrates, Fiber, Fat, Fatty Acids, Cholesterol, Protein, and Amino Acids. Washington, DC: National Academy Press, 2002.

28 Institute of Medicine. Dietary Reference Intakes for Calcium, Phosphorus, Magnesium, Vitamin D, and Fluoride. Washington, DC: National Academy Press, 1997.

29 Institute of Medicine. Dietary Reference Intakes for Vitamin A, Vitamin K, Arsenic, Boron, Chromium, Copper, Iodine, Iron, Manganese, Molybdenum, Nickel, Silicon, Vanadium, and Zinc. Washington, DC: National Academy Press, 2001.

30 Institute of Medicine. Dietary Reference Intakes for Vitamin C, Vitamin E, Selenium, and Carotenoids. Washington, DC: National Academy Press, 2000.

31 Institute of Medicine. Dietary Reference Intakes for Thiamin, Riboflavin, Niacin, Vitamin B6, Folate, Vitamin B12, Pantothenic Acid, Biotin, and Choline. Washington, DC: National Academy Press, 1999.

32 Gordon BH, Kang MS, Cho P, Sucher KP. Dietary habits and health beliefs of Korean-Americans in the San Francisco Bay Area. Journal of the American Dietetic Association 2000; 100: 1198-201

33 Yang EJ, Kim WY, Song WO. Health risks in relation to dietary changes in Korean Americans. Korean Journal of Dietary Culture 2001; 16: 515-24 (in Korean).

34 World Health Organization (WHO). Diet, Nutrition and the Prevention of Chronic Diseases. Report of the Joint WHO/FAO Expert Consultation. WHO Technical Report Series, No. 916. Geneva: WHO, 2003. Also available at http:// www.who.int/dietphysicalactivity/publications/trs916/ download/en/

35 Lauderdale DS, Rathouz PJ. Body mass index in a US national sample of Asian Americans: effects of nativity, years since immigration and socioeconomic status. International Journal of Obesity and Related Metabolic Disorders 2000; 24: 1188-94.

36 Wismer BA, Moskowitz JM, Chen AM, Kang SH, Novotny TE, Min K, et al. Rates and independent correlates of Pap smear testing among Korean-American women. American Journal of Public Health 1998; 88: 656-60.

37 United States Department of Health and Human Services and United States Department of Agriculture. Dietary Guidelines for Americans 2005 [online]. Available at http://www.health.gov/dietaryguidelines/dga2005/document/. Accessed 10 March 2005.

38 Schultz JD, Spindler AA, Josephson RV. Diet and acculturation in Chinese women. Journal of Nutrition Education 1994; 26: 266-72.

39 Yang W, Read M. Dietary pattern changes of Asian immigrants. Nutrition Research 1996; 16: 1277-93.

40 Institute of Medicine. Dietary Reference Intakes for Water, Potassium, Sodium, Chloride, and Sulfate. Washington, DC: National Academy Press, 2004. 